\title{
TÌNH TRẠNG DINH DƯỡNG VÀ MỘT SỐ YẾU TỐ LIÊN QUAN ĐẾN SUY DINH DƯỠNG THỂ NHE CẦN CỦA TRẺ TỪ 0-24 THÁNG TẠI XÃ VĨNH HÀO, HUYỆN VỤ BẢN TİNH NAM ĐỊNH NĂM 2021
}

\section{TÓM TẮT}

Nghiên cứu được thực hiện trên 214 trẻ em từ 0 đến 24 tháng tuổi và các bà mẹ tại xã Vĩnh Hào, huyên Vu Bản, tỉnh Nam Định năm 2020 nhằm mục tiêu đánh giá tình trạng dinh dưỡng và tìm hiểu các yếu tố liên quan đến suy dinh dưỡng thể nhe cân bằng phương pháp điều tra mô tả cắt ngang. Kết quả nghiên cứu cho thấy tỷ lệ suy dinh dưỡng (SDD) thể nhẹ cân $(\mathrm{CN} / \mathrm{T})$ là $9.8 \%$, tỷ lệ SDD thấp còi $(\mathrm{CC} / \mathrm{T})$ là 9.3 tỷ lệ SDD gày còm (CN/CC) là $9.3 \%$. SDD được thấy chủ yếu ở trẻ sau 6 tháng và tăng dần đến 24 tháng. Tỷ lệ bà me cho trẻ bú sớm trong vòng 1 giờ đầu sau sinh là $31.8 \%$. Nghiên cứu cũng cho thấy tỷ lệ trẻ ăn bổ sung trước 6 tháng là $80.4 \%$. Nghiên cứu chưa tìm thấy mối liên quan giữa việc bú sớm sau sinh và ăn bổ sung sớm đến tỷ lệ suy dinh dưỡng thể nhẹ cân ở trẻ.

Tư khóa: tình trạng dinh dương, suy dinh dương, 0-24 tháng

\section{SUMMARY}

NUTRITIONAL STATUS AND SOME

FACTORS RELATED TO UNDERWEIHT

MALNUTRITION OF CHILDREN FROM 0 TO

\section{MONTHS IN VINH HAO COMMUNE, VU}

\section{BAN DISTRICT OF NAM DINH PROVINCE}

To asess the nutritional status and some factors related to underweight malnutrition of children from 0 to 24 months in Vinh Hao commune, Vu Ban district of Nam Dinh province. Method: Cross - sectional descriptive study with 214 child- mother pairs. Results: The prevalence of manutrition of children from 0 to 24 months was $9.8 \%$ by WAZ, $9.3 \%$ by HAZ and $9.3 \%$ by $\mathrm{WHZ}$. The percentage of mothers who breastfeed their babies within the first hour after birth is $31.8 \%$. The percentage of children who have been receving supplementary food before 6 months is $80.4 \%$. The research had not found out the statical relation between childs malnutrition status with early complementary feeding.

Keywords: nutritional status, malnutrition, 0-24 months

\section{I. ĐẶT VẤN ĐỀ}

Suy dinh dương (SDD), ở trẻ dưới 24 tháng tuổi vẫn còn phổ biến ở trên thế giới cũng như

\footnotetext{
*Trường Đại học Điều dướng Nam Định Chịu trách nhiệm chính: Vũ Thị Nhung Email: vunhung87ytcd@gmail.com Ngày nhận bài: 3.5.2021 Ngày phản biện khoa học: 23.6.2021 Ngày duyệt bài: 5.7.2021
}

\section{Vũ Thị Nhung*, Trần Thị Nhi*}

tại Việt Nam. Mặc dù suy dinh dưỡng trên thế giới đang có xu hướng giảm theo thời gian, tuy nhiên vấn đề suy dinh dưỡng ở trẻ dưới 24 tháng tuổi vẫn là mối quan tâm không chỉ của ngành dinh dưỡng mà cả xã hội. Tại Việt Nam, những năm gân đây cùng với sự phát triển kinh tế và triển khai các chương trình phòng chông suy dinh dưỡng thì tỷ lệ SDD ở trẻ em dưới 5 tuổi đã giảm xuống một cách đáng kể. Từ $17.5 \%$ năm 2010 xuống còn $12.8 \%$ năm 2018 [1]. Tuy nhiên, Việt Nam vẫn được coi là quốc gia có tỷ lệ SDD cao trong khu vực. Các nghiên cứu về dinh dưỡng cho thấy những trẻ SDD 2 năm đâu đời sẽ ảnh hưởng lớn đến phát triển thể lực sau này đặc biệt là chiều cao của trẻ vị thành niên. Nghiên cứu được thực hiện tại xã Vinh Hào, huyện Vụ Bản, là xã được coi là có điều kiện kinh tế hơn so với xã lân cận do có làng nghề và khu công nghiệp gân kề, vì vậy đề tài được thực hiện nhằm mục tiêu:

1. Đánh giá thực trạng tình trạng dinh dương của trẻ từ 0 đến 24 tháng tại xã Vînh Hào, huyện Vu Bản, tinh Nam Định

2. Tìm hiêu mối liên quan giữa tình trạng dinh dướng và hành vi chăm sóc tré tư 0 đên 24 tháng tuôi

\section{II. ĐỐI TƯợNG VÀ PHƯƠNG PHÁP NGHIÊN CỨU}

1. Địa điểm nghiên cứu. Nghiên cứu được tiến hành chủ đích tại xã Vĩnh Hào, huyện Vụ Bản, tỉnh Nam Định.

\section{2. Đối tượng và thời gian nghiên cứu}

- Trẻ em từ 0-24 tháng tuổi.

Bà mẹ có con trong độ tuổi từ 0-24 tháng tuổi (hoặc người trực tiếp chăm sóc trẻ) tại xã Vĩnh Hào, huyên Vụ Bản, tỉnh Nam Định.

Tiêu chuấn loại trừ

- Bà mẹ (hoăc người trực tiếp chăm sóc trẻ) không đủ sức khỏe hoặc không có khả năng trả lời các câu hỏi.

- Trẻ mắc các bệnh bẩm sinh, đang mắc các bệnh cấp tính, mãn tính tại thời điểm nghiên cứu.

- Đối tượng từ chối tham gia nghiên cứu.

3. Thời gian nghiên cứu. Nghiên cứu được thực hiện trong thời gian từ tháng 5/2020 tới tháng 7/2020.

4. Thiết kế nghiên cứu: Nghiên cứu cắt ngang mô tả. Nghiên cứu được thực hiện nhằm 
tìm hiểu thực trạng suy dinh dưỡng và các yếu tố liên quañ.

\section{Cỡ mẫu và chon mẫu}

Cõ mẫu được tính theo công thức

$$
n=z_{1-\infty / 2}^{2} \frac{p(1-p)}{(d)^{2}}
$$

Trong đó: n: Số trẻ cần điều tra

+ Z1-a/2: Giá Ứng với độ tin cậy $95 \%$ ( $a=$ $0,05)$ thì $Z_{1-\mathrm{a} / 2}=1,96$

+ $p$ : Tỷ lệ nhẹ cân của trẻ em huyện Vụ Bản năm $2019, p=0,113$

$\mathrm{d}$ : chọn $\mathrm{d}=0,05$

Thay các giá trị trên vào công thức tính cõ mẫu ta được cỡ mẫu nghiên cứu là 154 trẻ. Thêm $10 \%$ có thể từ chối, bỏ cuộc, thực tế cõ mấu điều tra lấy tròn 214 trẻ.

Chọn mẫu: Lập danh sách toàn bộ trẻ từ 024 tháng tuổi trên địa bàn xã Vĩnh Hào, huyện Vụ Bản, tỉnh Nam Định tại thời điểm 20/5/2020 thỏa mãn các tiêu chí lựa chọn đối tượng, chọn mẫu theo phương pháp ngấu nhiên hệ thống. Trong danh sách trẻ từ 0-24 tháng tuổi đã lâp của mỗi xã, sử dụng phương pháp chọn mẫu ngẫu nhiên chọn ra một trẻ đâu tiên trong danh sách, sau đó áp dụng khoảng cách $\mathrm{k}=2$ (cứ 2 trẻ thì mời 1 trẻ ra phỏng vấn) chọn ra đủ số trẻ dự kiến như ban đầu.

\section{Phương pháp thu thập số liệu}

- Nhóm thông tin về nhân khẩu học: sử dụng phiếu hỏi phỏng vấn bà mẹ để thu thập các thông tin về tuổi, giới, địa chỉ của trẻ.

- Các chỉ số nhân trắc: trẻ được cân đo chiều dài để xác định tình trạng dinh dưỡng.

- Phương pháp đánh giá: Sử dụng các số đo tháng tuổi, cân nặng, chiều cao của trẻ và phân loại theo WHO 2006 với các chỉ số: WAZ (Z-score cân nă̆ng theo tuổi), HAZ (Z-score chiều cao theo tuổi), WHZ(Z- score cân nặng theo chiều cao). Số liệu được nhập vào phần mềm Anthro của WHO năm 2006 sau đó được đánh giá theo phân loại của WHO so với chuẩn tăng trưởng WHO 2006 để đánh giá tình trạng dinh dưỡng [2].

\section{Bảng 3.2. Trung bình cân năng, chiều cao và Zscore $(X \pm S D)$ của trẻ theo giới}

\begin{tabular}{|c|c|c|c|}
\hline Chỉ số & Nam (n=102 ) & Nữ $(\mathbf{n = 1 1 2})$ & Chung (n=214 ) \\
\hline Cân nặng TB (kg) & $9.03 \pm 2.2$ & $8.6 \pm 1.9$ & $8.8 \pm 2.03$ \\
\hline Chiều cao TB (kg) & $73.6 \pm 8.3$ & $73.6 \pm 8.5$ & $73.6 \pm 8.4$ \\
\hline WAZ (Zscore) & $-0.32 \pm 1.01$ & $-0.33 \pm 0.97$ & $-0.33 \pm 0.99$ \\
\hline HAZ (Zscore) & $0.18 \pm 1.28$ & $0.12 \pm 1.26$ & $0,07 \pm 1.27$ \\
\hline WHZ (Zscore) & $-0.46 \pm 1.29$ & $-0.54 \pm 1.03$ & $-0.51 \pm 1.16$ \\
\hline
\end{tabular}

Nhận xét: Cân nặng trung bình của trẻ là của trẻ là $73.6 \pm 8.4 \mathrm{~cm}$, trẻ nam có chiêu cao $8.8 \pm 2.03 \mathrm{~kg}$, trong đó trẻ nam là $9.03 \pm 2.2 \mathrm{~kg}$ và trẻ gái là $8.6 \pm 1.9 \mathrm{~kg}$. Chiều cao trung bình
- Phỏng vấn trực tiếp bà mẹ về một số yếu tố nguy cơ liên quan đến tình trạng SDD nhẹ cân qua bộ câu hỏi về thực hành nuôii trẻ được thiết kế trước. Bộ câu hỏi được xây dựng dựa trên hướng dẫn của UNICEF năm 1999[3]

6. Xử lý và phân tích số liệu

- Số liêu được nhập bằng phần mềm excel.

- Số liệu về nhân trắc học được xử lý bằng phần mềm Anthro của WHO, 2006.

- Tất cả các số liệu được chuyển và phân tích bằng phần mềm SPSS 20.0.

\section{KẾT QUẢ NGHIÊN CỨU}

1. Tình trạng dinh dưỡng của trẻ

Bảng 3.1. Thông tin chung về trẻ

\begin{tabular}{|c|c|c|}
\hline \multicolumn{1}{|c|}{ Chỉ số } & $\begin{array}{c}\text { Tân số } \\
(\mathbf{n = 2 1 4 )}\end{array}$ & $\begin{array}{c}\text { Tỷ lệ } \\
(\mathbf{\%})\end{array}$ \\
\hline Tuối: 0-6 tháng & 53 & 24.8 \\
\hline 7- 12 tháng & 60 & 28 \\
\hline 13-24 tháng & 101 & 47.2 \\
\hline Giơoi: Nam & 102 & 47.7 \\
\hline Nữ & 112 & 52.3 \\
\hline Tống & $\mathbf{2 1 4}$ & $\mathbf{1 0 0}$ \\
\hline
\end{tabular}

Nhân xét: Có 214 trẻ tham gia đánh giá tình trạng dinh dưỡng, phân bố trẻ nữ cao hơn trẻ nam, lần lượt là 52.3 \% nữ và $47.7 \%$ nam.

Biểu đồ 3.1. Tình trạng suy dinh dưỡng của trẻ tai xã Vĩnh Hào

Nhận xét: Biểu đồ trên cho thấy có $9.8 \%$ trẻ nhẹ cân và $9.3 \%$ trẻ bị suy dinh dưỡng thấp còi, $9.3 \%$ trẻ SDD thể gày còm. Tỷ lệ thừa cân ở lứa tuổi này chiếm $3.2 \%$.

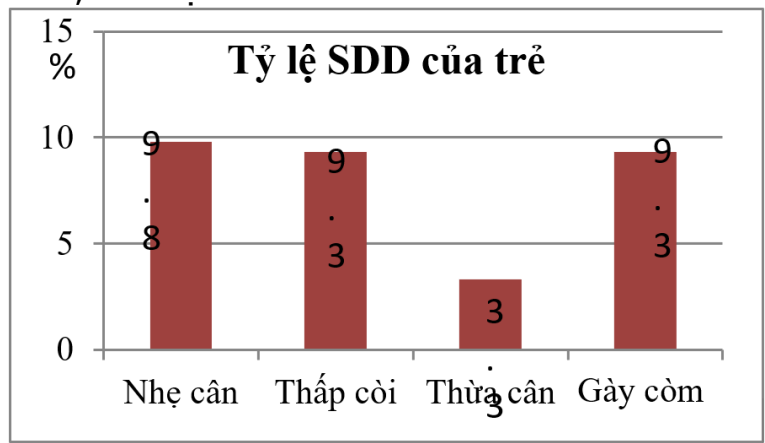

$73.6 \pm 8.3$ tương đương so với trẻ nữ $73.6 \pm 8.5$.

Giá trị trung bình của $W A Z, H A Z, W H Z$ lần 
lượt là $-0.33 \pm 0.99 ; 0.12 \pm 1.26$; và $-0.54 \pm$ 1.03. Tuy nhiên, không có sự khác biệt về
Zscore trung bình của 3 thể $W A Z, H A Z$ và $W H Z$ giữa trẻ trai và trẻ gái $(p>0,05)$.

Bảng 3.3. Phân bố tình trạng suy dinh dưỡng của trẻ ở cả 3 thể theo nhómtuổi $(n=214)$

\begin{tabular}{|c|c|c|c|c|c|c|c|c|}
\hline Nhóm tuổi & \multicolumn{2}{|c|}{$\begin{array}{c}\text { SDD thể nhẹ } \\
\text { cân }\end{array}$} & \multicolumn{2}{c|}{$\begin{array}{c}\text { SDD thể thấp } \\
\text { còi }\end{array}$} & \multicolumn{2}{c|}{$\begin{array}{c}\text { SDD thể gày } \\
\text { còm }\end{array}$} & \multicolumn{2}{c|}{ Thừa cân } \\
\hline & $\mathbf{n}$ & $\mathbf{\%}$ & $\mathbf{n}$ & $\mathbf{\%}$ & $\mathbf{n}$ & $\mathbf{\%}$ & $\mathbf{n}$ & $\%$ \\
\hline 0-6 tháng $(\mathrm{n}=53)$ & 1 & 0.5 & 1 & 0.5 & 4 & 1.9 & 1 & 0.5 \\
\hline 7- 12 tháng $(\mathrm{n}=60)$ & 7 & 3.2 & 6 & 2.8 & 7 & 3.2 & 4 & 1.9 \\
\hline 13-24tháng $(\mathrm{n}=101)$ & 13 & 6.1 & 13 & 6.1 & 9 & 4.2 & 2 & 0.9 \\
\hline Tổng & 21 & $\mathbf{9 . 8}$ & 20 & $\mathbf{9 . 3}$ & 21 & $\mathbf{9 . 3}$ & 7 & $\mathbf{3 . 3}$ \\
\hline
\end{tabular}

Nhận xét: Kết quả bảng 3.3 cho thấy tỷ lệ SDD của trẻ từ 0-6 tháng tuối là thấp nhất ở cả 3 thể và có xu hướng tăng dân theo nhóm tuổi. Với SDD thể nhe cân, trong 21 trẻ bị SDD, tỷ lê ở nhóm tuổi 0 - 6 tháng là 1,9\%, tăng lên 12,8\% ở lứa tuổi 13-24 tháng. Điêu này tương tự đối với SDD thể thấp còi, lứa tuổi gặp suy dinh dưỡng nhiêu nhất là $12-24$ tháng với $12.8 \%$. Ở cả 3 nhóm tuổi đều xuất hiện trẻ bị thừa cân, tỷ lệ chung cho cả 3 nhóm là 3.3\%.

2. Một số yếu tố nguy cớ của SDD nhẹ cân ở trè.

Bảng 3.6. Thông tin chung về trẻ tham gia nghiên cứu

\begin{tabular}{|c|c|c|c|c|c|c|c|c|}
\hline \multirow{2}{*}{\multicolumn{2}{|c|}{ Chỉ số }} & \multicolumn{2}{|c|}{$\begin{array}{c}\text { SDD nhe cân } \\
(\mathbf{n}=\mathbf{2 1})\end{array}$} & \multicolumn{2}{|c|}{$\begin{array}{c}\text { Không SDD } \\
(n=193)\end{array}$} & \multicolumn{2}{|c|}{ Chung } & \multirow[t]{2}{*}{$\mathbf{p}^{\mathrm{a}}$} \\
\hline & & $\mathrm{n}$ & $\%$ & $\mathbf{N}$ & $\%$ & $\mathbf{N}$ & $\%$ & \\
\hline \multirow{2}{*}{$\begin{array}{l}\text { Bú sớm sau sinh } \\
(\mathrm{n}=214)\end{array}$} & Tron & 4 & 19 & 64 & 33.2 & 68 & 31.8 & \multirow{2}{*}{$>0.05$} \\
\hline & & 17 & 80.9 & 129 & 6 & 14 & & \\
\hline \multirow{2}{*}{$\begin{array}{c}\text { Thời điếm ăn bố } \\
\text { sung }(\mathrm{n}=)\end{array}$} & & $\frac{19}{2}$ & 90.5 & 153 & 88.9 & 172 & 80.4 & \multirow{2}{*}{$>0,05$} \\
\hline & $\geq 6$ tháng & 2 & 9.5 & 40 & 11.5 & 42 & 19.6 & \\
\hline
\end{tabular}

Có $31.8 \%$ trẻ tham gia nghiên cứu được bú trong vòng $1 \mathrm{~h}$ đầu sau sinh, trong số đó chỉ có $19 \%$ trẻ được bú mẹ trong vòng một giờ đầu, còn lại 81 trẻ bú me sau 1 giờ đầu. Có $80.4 \%$ trẻ SDD ăn bổ sung trước 6 tháng trong số đó có $90.5 \%$ trẻ ABS trước 6 tháng ở nhóm trẻ SDD thể nhe cân và tỷ lệ này ở nhóm không SDD là 9.5\%. Không có sự khác biệt có ý nghĩa thống kê về thời gian bú sớm sau sinh và thời điểm ăn bổ sung giữa 2 nhóm SDD và không SDD.

\section{BÀN LUÂN}

1. Tình trang dinh dưỡng của trẻ từ $0-6$ tháng tuổi tại xã Vĩnh Hào, huyện Vụ Bản năm 2020. Trẻ em trên toàn thế giới sẽ có tình trạng dinh dưỡng và chiều cao tối đa nếu được nuôi dưỡng trong môi trường lành mạnh và được chăm sóc tốt về y tế và dinh dưỡng. Để có hiệu quả tốt nhất các can thiệp phòng chống suy dinh dưỡng cần được tiến hành sớm, tốt nhất là từ khi trong bào thai tới khi trẻ được tròn 2 tuổi. Hiện nay SDD vẫn đang là vấn đề nghiêm trọng trên toàn cầu, suy dinh dưỡng lấy đi cuộc sống của 2.6 triệu trẻ em hàng năm và điều này hoàn toàn có thể phòng chống được[4]. Nghiên cứu của chúng tôi được thực hiện nhằm đánh giá tình trạng suy dinh dưỡng của trẻ ở cả ba thể cân nặng theo tuổi (thể nhe cân), cân nặng theo chiều cao (thể gày còm) và chiêu cao theo tuổi (thể thấp còi). Đã có 214 trẻ từ 0 đến 24 tháng thuộc xã Vĩnh Hào huyện Vụ Bản, tỉnh Nam Định tham gia nghiên cứu. Cân nặng trung bình của trẻ trong nghiên cứu là $8.8 \pm 2.03 \mathrm{~kg}$. Chiều cao trung bình là $73 \pm 8.4 \mathrm{~cm}$. Giá trị trung bình Zscore cân nặng theo tuổi, chiều cao theo tuổi và cân nặng theo chiều cao đều có giá trị âm lần lượt là $-0.33 \pm 0.99 ; 0,07 \pm 1.27$ và $-0.51 \pm$ 1.16 , kết quả này cao hơn báo cáo của Trần Thành Đô về xu hướng Z-score trung bình của trẻ em từ năm 2003 đến 2011 [5]. Điêuu này cho thấy, cùng với sự phát triển kinh tế xã hội, kiến thức chăm sóc của các bà me cũng đã được cải thiện, nên tình trạng dinh dưỡng của trẻ được cải thiện. Tỷ lệ suy dinh dưỡng thể nhe cân của trẻ tham gia nghiên cứu là $9.8 \%$ trong đó chỉ có 1 trẻ bị SDD nhe cân vừa còn lại là thể nhẹ. Tỷ lệ này thấp một phần là do xã Vĩnh Hào là một xã có làng nghề và có khu công nghiệp gần địa bàn xã, người dân trong độ tuổi sinh đẻ đi làm công nhân ở tỷ lệ cao, thu nhập được ổn định nên đời sống cơ bản được đảm bảo, do đó điều kiện chăm sóc trẻ được cải thiện. Tỷ lệ suy dinh dưỡng ở trẻ nam và ở trẻ nữ trong nghiên cứu không có sự khác biệt có ý nghĩa thống kê. Kết quả này tương tự như trong nghiên cứu của Nguyễn Thị Hào tại Thanh Hoá năm 2013 [6]. Xét theo từng độ tuổi của trẻ, kết quả nghiên cứu cho thấy tỷ lệ suy dinh dướng nhe cân tăng 
dần theo độ tuổi, tỷ lệ thấp nhất ở độ tuổi 0-6 tháng tuổi. Kết quả này cũng phù hợp với một số nghiên cứu [5][7]. Điều này là do trẻ dưới 6 tháng tuổi vẩn luôn là đối tượng được ưu tiên, được chăm sóc tốt nhất do trẻ vần bú mẹ là chủ yếu và lúc này mẹ vẫn còn được chế độ nghỉ thai sản nên giành nhiều thời gian chăm sóc trẻ hơn. Trẻ trên 6 tháng tuổi, lúc này mẹ đã đi làm bình thường trở lại, cùng với việc sữa mẹ không còn đáp ứng đủ cho nhu cầu ngày càng tăng của trẻ, trẻ bắt đầu ăn bổ sung, và lúc này trẻ cũng dễ bị ốm do giảm dần kháng thể từ mẹ chuyển qua sữa, cùng với nhiều yếu tố nguy cớ từ việc tiếp xúc với những yếu tố không có lợi cho sức khỏe như thời tiết, vi sinh vật... trong khi khả năng tiêu hóa của trẻ còn chưa hoàn chỉnh nên ảnh hưởng rất nhiêu đến khả năng tiêu hóa hấp thu và dẫn đến tỷ lệ SDD nhẹ cân có xu hướng tăng nhe qua các lứa tuổi.

Tỷ lệ suy dinh dưỡng thể thấp còi của trẻ tham gia nghiên cứu là 9.3\%. Trong nghiên cứu của chúng tôi, có thể thấy tỷ lệ SDD ở nam cao hơn của nữ tuy nhiên sự khác biệt này chưa có ý nghĩa thống kê $P>0.05$, kết quả này cũng tương tự như của một số tác giả như Nguyễn Thị Hào tại Thanh Hoá năm 2013[6], Trần Thị Tuyết Mai tại Khánh Hoà [8].

2. Một số yếu tố nguy cơ liên quan tới tình trạng SDD nhẹ cân ở trẻ tại xã Vĩnh Hào, huyện Vụ Bản năm 2020.

Nuôi con bằng sữa mẹ. Bú sớm trong vòng một giờ sau sinh là một trong 10 bước để đánh giá "Nuôi con bằng sữa me thành công" do Quỹ Nhi đồng Liên Hợp quốc phát động từ những năm 1989, đồng thời cũng là yếu tố tác động tới tình trạng SDD ở trẻ. Tỷ lệ trẻ trong nghiên cứu được bú me trong vòng $1 \mathrm{~h}$ đầu sau sinh là $31,8 \%$. Tỷ lể này thấp hơn với nghiên cứu của tác giả Nguyễn Anh Vũ khi nghiên cứu tại Hưng Yên là $48.5 \%[9]$, thấp hơn nhiều so với báo cáo của dự án Alive and Thrive tại 4 tỉnh năm 2010 là $58,5 \%$ và tại 11 tỉnh là $50,5 \%$. Tuy nhiên lại phù hợp với một số tác giả khác. Việc các bà mẹ không cho trẻ bú sớm ngay sau sinh một phần do các bệnh viện tuyến huyện chưa áp dụng biện pháp sinh da kề da, dó đó thời gian ngay sau sinh em bé thường không nằm cùng mẹ, điều này dẫn đến tỷ lệ trẻ được bú me trong vòng một giờ đầu sau sinh không cao như khuyến cáo. Nhiều bà mẹ quan niệm sữa đầu tiên trong những giờ đầu có ít và không đủ cho trẻ, và khi trẻ khóc sau sinh là do đói cùng với lúc đó người mẹ vẫn còn mệt và đau sau cuộc chuyển dạ nên nhiều mẹ do thiếu kiến thức đã cho trẻ ăn, uống thay thế sữa mẹ bằng thực phẩm khác như sữa công thức. Điều này làm ảnh hưởng tới sức khỏe của trẻ, khiến trẻ không nhận được sữa non- loại sữa có nhiều giá trị dinh dưỡng và miễn dịch từ mẹ. Trong nghiên cứu của chúng tôi mặc dù sự khác biệt về tỷ lệ SDD giữa trẻ được bú me sớm trong một giờ đầu và không được bú sớm không có ý nghĩa về mặt thống kê nhưng có thể thấy rằng tỷ lệ trẻ SDD trong nhóm bú me trong 1 giờ đầu cao hơn hẳn nhóm còn lại $33.2 \%$ so với $19 \%$.

Ăn bổ sung. Nghiên cứu của chúng tôi chưa tìm ra mối liên quan giữa thời điểm cho trẻ ăn bổ sung với tình trạng SDD nhe cân ở trẻ. Tỷ lệ trẻ được cho ăn từ trước 6 tháng trong nghiên cứu của chúng tôi là $80.4 \%$. Mặc dù điều kiện kinh tế cải thiện, các bà me đã quan tâm nhiểu hơn tới sức khỏe của bản thân và của em bé, tuy nhiên một số bà mẹ làm nông nghiệp hay công nhân có tâm lý cho trẻ ăn sớm để con quen dần khi me đi làm và để con quen với việc me sẽ đi làm trở lại dẫn đến tỷ lệ tương đối cao trẻ ăn bổ sung khi chưa tròn 6 tháng, và kết quả của nghiên cứu cũng phù hợp với nghiên cứu của Nguyễn Lân tại Thái Nguyên cho thây tỷ lệ các bà mẹ cho con ăn bổ sung sớm rất cao: có tới 4,5\% số trẻ ăn bổ sung trong tháng đầu, 13,5\% trong thời gian 1-2 tháng tuổi, trong 4 tháng đâu có tới $88,9 \%$ số trẻ được ăn bổ sung.

\section{KẾT LUÂ̂N}

\section{Tình trạng dinh dưỡng của trẻ từ 0-24} tháng tuổi:

- Tỷ lệ SDD thể nhe cân là 9.8\%; 9.3\% trẻ bị SDD thấp còi; $9.3 \%$ trẻ gày còm và $3.2 \%$ trẻ thừa cân. Tỷ lệ SDD thể nhẹ cân và thấp còi đều thấp nhất ở nhóm tuổi 0-6 tháng tháng và tăng theo nhóm tuổi.

- Tỷ lệ cho trẻ bú sớm trong vòng 1 giờ đầu sau sinh là $31.8 \%$, tỷ lệ ăn bổ sung trước 6 tháng là $80.4 \%$

2. Các yếu tố liên quan tới tình trạng SDD nhẹ cân của trẻ:

Chưa tìm thấy mối liên quan ở mức có ý nghĩa thống kê giữa tình trạng dinh dưỡng và các yếu tố liên quan đến chăm sóc trẻ.

KHUYẾN NGHI. Tuyên truyền rộng rãi đến các bà me trong độ tuổi sinh đẻ về kiến thức nuôi con bằng sữa me, hướng dẫn thực hành dinh dưỡng cho các bà me và người trực tiếp chăm sóc trẻ về lợi ích của việc cho trẻ bú sớm sau sinh và ăn bổ sung hợp lý từ khi trẻ tròn 6 tháng để trẻ có sức khỏe và tình trạng dinh dưỡng được tốt nhất. 


\section{TÀI LIẸU THAM KHẢO}

1. Viện Dinh Dưỡng (2018). Số liệu thống kê về tình trạng dinh dướng trẻ em qua các năm, $<$ http://viendinhduong.vn/news/vi/106/61/0/a/solieu-thong-ke-ve-tinh-trang-dinh-duong-tre-emqua-cac-nam.aspx\%3E, 30/7/2018.

2. De Onis M., Blössner M. (2003). The World Health Organization Global Database on Child Growth and Malnutrition: methodology and applications International Journal of Epidemiology, 32, 518-526.

3. UNICEF (1999). Multiple indicator cluster survey manual New York, 5-10.

4. Bộ Y Tế (2019). Dinh dưỡng lâm sàng. Nhà xuất ban Y hoc, Hà Nôi.

5. Trân Thành Đồ, Lê Danh Tuyên và Nguyễn Phương Hoa (2012). Xu hướng thay đổi gia tri trung bình Z-score trong đánh giá tình trạng dinh dưỡng ở trẻ em năm 2003 -2011. Dinh dưỡng và Thực phẩm, 8(2), 23-28.

6. Nguyê̂n Thị Haoo (2013). Tình trang dinh dưỡng của trẻ dưới 5 tuổi và các yếu tố liền quan tới suy dinh dưỡng thấp còi của trẻ 6-23 tháng tuối tai 2 huyện của tỉnh Thanh Hóa năm 2013, Luận văn Thạc sĩ, Đại hoc Y tế công công.

7. Lê Thi Thu Hà (2014) Tînh trạng dinh dưỡng và môtt số yếu tố nguy cơ tới suy dinh dưỡng thấp còi của trẻ 12 -24 tháng tuổi tai Tam Đảo, Vinh Phúc

8. Trân Thị Tuyết Mai (2013). Xây dựng và đánh gía hiêu quả mô hình truyền thông đa dang tai tuyến y tế cơ sở trong phòng chống suy dinh dưỡng trẻ em tỉnh Khánh Hoà, Luận án Tiến sĩ, Đại học Y tế công cộng.

9. Nguyễn AnhVữ và Lê Thị Hương (2011). Tình trang dinh dưỡng và môt số yếu tố liên quan của trẻ em dưới 5 tuổi tai huyên Tiên Lữ tỉnh Hưng Yên. Dinh dưỡng và Thực phẩm, 7(1), 13-17.

\title{
KHẢO SÁT ĐĂC ĐIỂM LÂM SÀNG CỦA NHÓM BÊNH NHÂN MẮC HộI CHỨNG ỐNG CỔ TAY MỨC Độ NẶNG VẦ RẤT NẶNG
}

\author{
Dương Đình Toàn ${ }^{1}$, Nguyễn Đình Hưng ${ }^{2}$, Hoàng Văn Ba ${ }^{2}$
}

\section{TÓM TẮT}

Chúng tôi đã tiến hành khảo sát đặc điểm lâm sàng trên 38 bệnh nhân với 42 bàn tay được chẩn đoán là hôi chứng ống cổ tay (OCT) mức đô năng và rất nặng. Mục tiểu: Khảo sát, đánh giá các biểu hiện lâm sàng, tẩn suất và các mối liên quan đối với các triệu chứng lâm sàng của 42 bàn tay mắc hội chứng OCT mức độ nặng và rất nặng. Phương pháp nghiên cứu: Thăm khám, ghi nhận các dấu hiệu lâm sàng của bệnh nhân mắc hội chứng OCT mức độ vừa và nặng. Kết quả: $100 \%$ bệnh nhân tê bì bàn tay tương ứng vùng chi phối cảm giác thần kinh giữa, 90,5\% teo cơ mô cái, tỷ lệ dương tính với các nghiệm pháp Tinel, Phalen, Durkan tương ứng là $66,7 \%$,

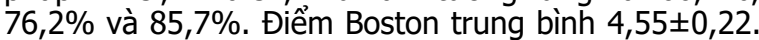
Kết luận: Đối với hội chứng OCT mức độ nặng và rất nặng, những biểu hiện lâm sàng gặp hẩu hết ở các bệnh nhân, chức năng bàn tay giảm mạnh.

\section{SUMMARY}

\section{SURVEYING CLINICAL CHARACTERISTICS OF THE PATIENTS WITH CARPAL TUNNEL SYNDROME IN SEVERE AND} VERY SEVERE STAGE

We conducted a survey of clinical characteristics on 38 patients with 42 hands diagnosed with severe and very severe carpal tunnel syndrome (CTS).

\footnotetext{
${ }^{1}$ Đại Họ Y Hà Nội

${ }^{2}$ BV Đa khoa Xanh Pôn

Chịu trách nhiệm chính: Dương Đình Toàn

Email: duongdinhtoan@hmu.edu.vn

Ngày nhận bài: 7.5.2021

Ngày phản biên khoa học: 25.6.2021

Ngày duyệt bài: 2.7.2021
}

Objective: To survey and evaluate the clinical manifestations, frequency and relationships to clinical symptoms of 42 hands with severe and very severe CTS. Method: Examination and recording of clinical signs of patients with severe and very severe CTS. Results: $100 \%$ of patients with hand numbness corresponds to the median nerve sensory region, $90.5 \%$ atrophy of the thenar eminence, the positive rate for Tinel, Phalen, Durkan tests is respectively $66.7 \%, 76.2 \%$ and $85.7 \%$. Average Boston score is $4.55 \pm 0.22$. Conclusion: For severe and very severe CTS, the most common clinical manifestations in patients, hand function decreased sharply.

\section{I. ĐĂT VẤN ĐỀ}

Hội chứng ống cổ tay (OCT) là tình trạng chèn ép thần kinh giữa khi nó đi qua ống cổ tay, đây là hội chứng hay gặp nhất trong các bệnh lý chèn ép dây thần kinh ngoại biên. Trong những năm gân đây, tỷ lệ mắc hội chứng ống cổ tay (HC OCT) ngày càng tăng cùng với sự phát triển của ngành nghề lao động tinh vi, không đòi hỏi sức lao động lớn nhưng yêu câu những động tác tỉ mỉ và sử dụng tính linh hoạt của cổ tay ngày càng nhiều. Thêm vào đó, trình độ dân trí, trình độ hiểu hiết về bệnh và chất lượng cuộc sống tăng lên khiến viêc phát hiện và chẩn đoán bênh lý này có xu hướng tăng lên. Tuy vậy, không ít người bệnh đến khám thường đã ở mức độ nặng và rất nặng, việc điều trị trở nên khó khăn hơn, hiêuu quả điều trị không như mong muốn. Chúng tôi thực hiện đề tài này nhằm mục tiêu khảo sát đánh giá các biểu hiện lâm sàng, tân suất và các mối liên quan đối với các triệu chứng lâm sàng 